\title{
A study on geospatial technology for detecting and mapping of Solenopsis mealybug (Hemiptera: Pseudococcidae) in cotton crop
}

\author{
S. K. Singh ${ }^{1 *}$, Sujay Dutta ${ }^{2}$ and Nishith Dharaiya ${ }^{1}$ \\ ${ }^{1}$ Department of Life Science, Hemchandracharya North Gujarat University, Patan-384265 (Gujarat), INDIA \\ ${ }^{2}$ Department of Life Science, Space Application Centre (ISRO), Ahmedabad- 380001 (Gujarat), INDIA \\ *Corresponding author. E-mail: sksingh0215@gmail.com
}

Received: April 1, 2016; Revised received: August 20, 2016; Accepted: November 22, 2016

\begin{abstract}
Detection of crop stress is one of the major applications of remote sensing in agriculture. Many researchers have confirmed the ability of remote sensing techniques for detection of pest/disease on cotton. The objective of the present study was to evaluate the relation between the mealybug severity and remote sensing indices and development of a model for mapping of mealybug damage using remote sensing indices. The mealybug-infested cotton crop had a significantly lower reflectance $(33 \%)$ in the near infrared region and higher (14\%) in the visible range of the spectrum when compared with the non-infested cotton crop having near infrared and visible region reflectance of $48 \%$ and $9 \%$ respectively. Multiple Linear regression analysis showed that there were varying relationships between mealybug severity and spectral vegetation indices, with coefficients of determination $\left(r^{2}\right)$ ranging from 0.63 to 0.31 . Model developed in this study for the mealybug damage assessment in cotton crop yielded significant relationship $\left(r^{2}=0.863\right)$ and was applied on satellite data of $21^{\text {st }}$ September 2009 which revealed high severity of mealybug and it was low on $24^{\text {th }}$ September 2010 which confirmed the significance of the model and can be used in the identification of mealybug infested cotton zones. These results indicate that remote sensing data have the potential to distinguish damage by mealybug and quantify its abundance in cotton.
\end{abstract}

Keywords: LST, Mealybug, MPSI-2, MPSI-8, Remote sensing, Severity index, TVDI

\section{INTRODUCTION}

Plants respond to pest and disease stress in a number of ways, including leaf curling, wilting, chlorosis or necrosis of photosynthetically active parts, stunted growth, or in some cases reduction in leaf area due to severe defoliation (Aggarwal et al., 2006). Many of these plant responses are difficult to visually quantify with acceptable levels of accuracy, precision, and speed. These responses also affect the amount and quality of electromagnetic radiation reflected from plant canopies. Cotton mealybug Phenacoccus Solenopsis spread from infected to healthy plants via the wind, irrigated water, rain, ants, and birds or by sticking/clinging to equipment, animals or people. Mealy bugs can feed on all parts of a plant, but prefer actively growing leaf tissue, petioles, and leaf veins. They damage the plants by sucking sap from leaves, twigs, stems, roots and fruiting bodies. They inject toxic saliva into the plant parts causing chlorosis, stunting, deformation and death of plants (Tanwar et al., 2007).

The first incidence of the Solenopsis mealy bug on cotton in India was recorded in 2005 in the northwestern state of Gujarat (Jhala et al., 2008) and subsequent damage was reported in 2007 in the state of Haryana where it infested 4800 ha (Monga et al., 2009). Mealybugs overrun the leaves, bolls, and branches, feed upon phloem sap and discharge extensive honeydew, on which dark dirty mold growth develops, accordingly influencing the photosynthetic capacity of the plant. Manifestations of plants infested during the vegetative stage incorporate distorted and bushy shoots crinkled curved leaves and hindered plants that dry totally in extreme cases. Late season indications incorporate plants with less and disfigured bolls, reduced vigor and early crop senescence. Mealybugs can also stain cotton lint and reduce quality (Kranthi et al., 2009; Charleston et al., 2010).

A regular monitoring of pest/disease infestation and damage is critically necessary. One method that has been used for a number of years for monitoring of pest/ disease outbreaks is to amount for the light reflected by the infested crop. The health of a crop can be determined by measuring the intensity of visible and nearinfrared (NIR) light reflected from leaves and studying changes in plant growth. Optical properties of healthy crops or leaves are characterized by high absorption in the blue $(400-500 \mathrm{~nm})$, increased reflection in the green (500-600 nm), high absorption in the red (600$700 \mathrm{~nm}$ ), and very high reflectance and transmittance in the NIR (700-1500 nm) (Gates, 1970). Spectral responses of the crop in the visible $(400-700 \mathrm{~nm})$ region are predominantly directed by the plenty of chlorophylls, carotenoids, and anthocyanins (Sims and Gam- 
on, 2002; Gamon and Surfus, 1999). The optical properties of crop or leaves in the NIR are due to the discontinuities between cell walls and intercellular air spaces in internal leaf structure (Pe nuelas and Filella, 1998). Changes in pigment concentrations as well as internal leaf structure are strongly interrelated to the physiological status (Blackburn, 1998a), and, consequently, spectral features of crop or leaves. During the interaction between stressors and their host plants, the physiological state of the infested tissue get altered, which reflects the changes in photosynthesis, transpiration, metabolism, and temperature (Pe nuelas and Filella, 1998). Ultimately, stressors lead to poor growth, loss of vigor, and finally death of plants (Richardson et al., 2004). Therefore, reflectance measurement seems to be very effective to differentiate stressed and unstressed plants or vegetation.

The objective of the present study was to evaluate the relation between mealy bug severity and remote sensing indices and development of a model for mapping of mealybug damage using remote sensing indices.

\section{MATERIALS AND METHODS}

Study area: Sirsa is situated in the northwestern part of Haryana State, India and confined within $29^{\circ} 13^{\prime}$ to $29^{0} 59^{\prime}$ North and $74^{0} 30^{\prime}$ to $75^{\circ} 7^{\prime}$ East (Fig. 1), lies in the arid, hot agro-ecological zone of India. It has two types of soils viz Sierozem and Desert soils. The sierozem soils are found throughout except southern part has desert soils. Ghaggar river is a major drainage. Cotton is the major crop in Kharif season (June-October) and sowing starts May to June and the picking starts in the month of October-November. The annual rainfall of the district is $318 \mathrm{~mm}$, about $80 \%$ received during the southwest monsoon and $20 \%$ rainfall received during the non-monsoon period due to western disturbances and thunderstorms. Mean minimum and maximum temperature is $5.1{ }^{\circ} \mathrm{C}$ and $41.1^{\circ} \mathrm{C}$

Field data collection: For calculation of mealybug

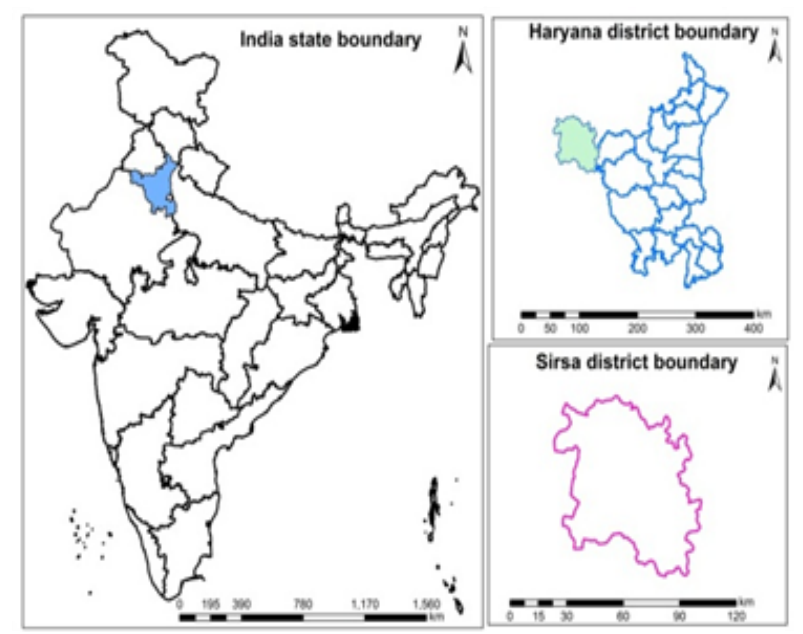

Fig. 1. Study area map. severity infestation, the ground survey was conducted to establish sampling plots. Initially healthy and infested crop locations were identified and then randomly locations were choosing for a sampling of mealybug severity. The geographic locations of healthy and infested cotton crop were recorded by handheld Global Positioning System (GPS) device. 100 plants were sampled for the severity index computation and grading of plant severity was given according to the infestation (Table 1). Severity Index (SI), an index of infestation level, was calculated based on equation 1-3. The range of SI varies from 1, low infestation to 4 , high infestation. Table 1 and Table 2 shows grading of mealybug infestation and general format for calculating severity index of mealybug. Severity Index was used to represent mealybug infestation on cotton crop instead of percentage infestation because severity index indicates infestation level while percentage infestation does not account for infestation level i.e. if 100 plants were graded as 1 then percentage infestation would be $100 \%$ while SI value would be 1 which shows low infestation of mealybug. Mealybug infested cotton crop, close and field view collected during ground observation is shown in fig. 2 .

Remote sensing data processing and preparation of

Table 1. Description of the symptoms of damage due to different levels of Solenopsis mealybug feeding effect in cotton. Source: Kranthi et al. (2009a).

\begin{tabular}{ll}
\hline $\begin{array}{l}\text { Level of } \\
\text { infestation }\end{array}$ & Symptoms of damage \\
Grade-0 & $\begin{array}{l}\text { Healthy Plant } \\
\text { About 1-10 mealybugs scattered over the } \\
\text { plan }\end{array}$ \\
Grade-2 & $\begin{array}{l}\text { At least one branch heavily infested with } \\
\text { mealybugs }\end{array}$ \\
Grade-3 & $\begin{array}{l}\text { Two or more branches heavily infested } \\
\text { with mealybug, crinkled or twisted top few } \\
\text { leaves with bunchy appearance, slight } \\
\text { sooty mold development }\end{array}$ \\
& $\begin{array}{l}\text { Complete plant infested, stunted growth with } \\
\text { sooty mold all over the plant, dry, reduced } \\
\text { crop vigor and early crop senescence }\end{array}$ \\
\hline
\end{tabular}

Table 2. General format of grades and plant infected.

\begin{tabular}{lccccc}
\hline Grades & 0 & 1 & 2 & 3 & 4 \\
Plant & $\mathrm{X} 1$ & $\mathrm{X} 2$ & $\mathrm{X} 3$ & $\mathrm{X} 4$ & $\mathrm{X} 5$ \\
\hline
\end{tabular}

Multiple, Percentage infestation and severity Index were calculated based on the following formula.

Multiple $=\mathrm{X} 2 *$ Grade $1+\mathrm{X} 3 * \mathrm{Grade} 2+\mathrm{X} 4 * \mathrm{Grade} 3+\mathrm{X} 5 *$ Grade 4 ....(1)

$\%$ Infestation=Infested Plant/Total Plant ....(2)

Severity Index (SI) = Multiple/Total Plant Infested ....(3) 


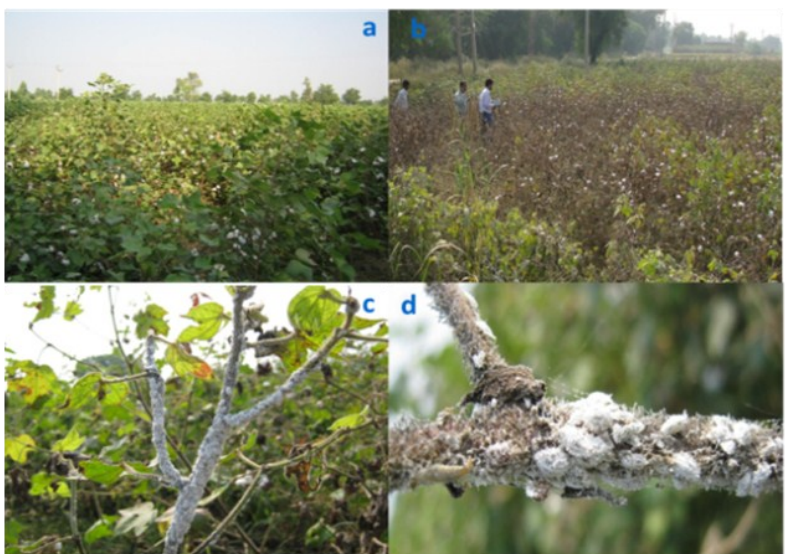

Fig. 2. (a) Healthy cotton crop (b) Field view of cotton crop damage by mealybug (c) Severely Infested cotton plant (d) close-up view of mealybug-infestation on cotton plant.

database: Landsat TM5 data with seven spectral bands viz. Blue, Green, Red, Near Infrared, Shortwave infrared, Thermal and Shortwave infrared bands. To monitor the crop condition, multi-date satellite data were downloaded for the year 2009 and 2010 respectively. For the pixel level reflectance conversion, FLAASH module, (Fast Line-of-Sight Atmospheric Analysis of Spectral Hypercubes) atmospheric correction module in ENVI 4.4 software was used. It adapts MODTRAN (MO Derate spectral resolution atmospheric TRAN Smittance) algorithm to satellite data and output in surface reflectance was obtained for individual satellite data. Spectral Vegetation Indices (SVIs) based on reflectance data (Table 3) were computed. ISODATA clustering technique in ERDAS Imagine 2011, image processing software was used for classification and preparation of land use land cover. Within the Cotton area, the mask was used to extract cotton pixel and SVIs and reflectance value of different band was extracted for different sites observed as mealybug infested and healthy cotton crop. The relationship between SVIs and SI were evaluated and finally used for the model development and validation.

Data analysis: Multiple linear regression analysis
(SPSS 16, statistics software) was performed on the mean value of SVIs from the healthy and infested cotton crop. The correlation coefficient (r) and coefficient of determination $\left(r^{2}\right)$ between the SI and SVIs were estimated from the data of different infested location (n =93), during the year 2009 and 2010. The model was developed and validated with blind data set was not used in model development.

\section{RESULTS AND DISCUSSION}

Reflectance profile of healthy and mealy bug infested cotton crop: Reflectance from the mealy buginfested and non infested cotton crop indicated that the spectral response of the mealy bug-infested cotton crop was significantly affected by mealy bug. The reflectance of the cotton crop in the NIR region was significantly lower in contrast to a significant increase in the visible spectrum due to mealy bug feeding (Fig.3). In SWIR region, the spectral response of the mealy buginfested cotton crop also shows a significant difference compared to the non-infested cotton crop which attributed to changes in leaf water content. Mealy buginfested cotton crop captured less or reflected more light than the non-infested cotton crop in NIR and visible region.

Relationship between severity index (SI) and

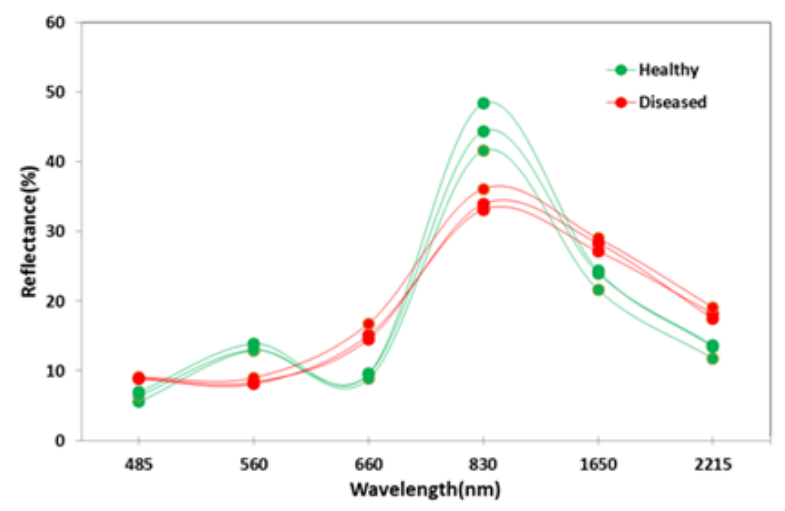

Fig. 3. Spectral reflectance profile of healthy and diseased crop.

Table 3. Spectral Vegetation indices used in the analysis.

\begin{tabular}{|c|c|c|}
\hline Index & Description & Reference \\
\hline MPSI-2 $=\frac{\left(\rho_{\text {nir }}-\rho_{\text {red }}\right)}{\left(\rho_{\text {swir }}+\rho_{\text {red }}\right)}$ & $\begin{array}{l}\text { Mealybug Pest Stress Index-2; sensitive to change in leaf } \\
\text { water content, chlorophyll content and leaf greenness }\end{array}$ & Present Study \\
\hline MPSI-8 $=\frac{\left(\rho_{\text {nir }}+\rho_{\text {green }}\right)-\left(\rho_{\text {swir }}+\rho_{\text {blue }}\right)}{\left(\rho_{\text {nir }}+\rho_{\text {green }}\right)+\left(\rho_{\text {swir }}+\rho_{\text {blue }}\right)}$ & $\begin{array}{l}\text { Mealybug Pest Stress Index-8; sensitive to change leaf water } \\
\text { content, chlorophyll content and leaf greenness }\end{array}$ & Singh et al., 2016 \\
\hline$T s=\frac{K_{2}}{\operatorname{Ln}\left(\varepsilon *\left(1+\frac{K_{1}}{L \lambda}\right)\right)}$ & $\begin{array}{l}\text { Land surface Temperature; sensitive to land surface tempera- } \\
\text { ture }\end{array}$ & Schott \& Volchok 1985 \\
\hline $\mathrm{TVDI}=\frac{\mathrm{Ts}-\mathrm{Tsmin}}{\mathrm{a}+\mathrm{bNDVI}-\mathrm{Tsmin}}$ & $\begin{array}{l}\text { Temperature Vegetation Dryness Index, sensitive to soil } \\
\text { moisture }\end{array}$ & Sandholt et al., 2002 \\
\hline
\end{tabular}



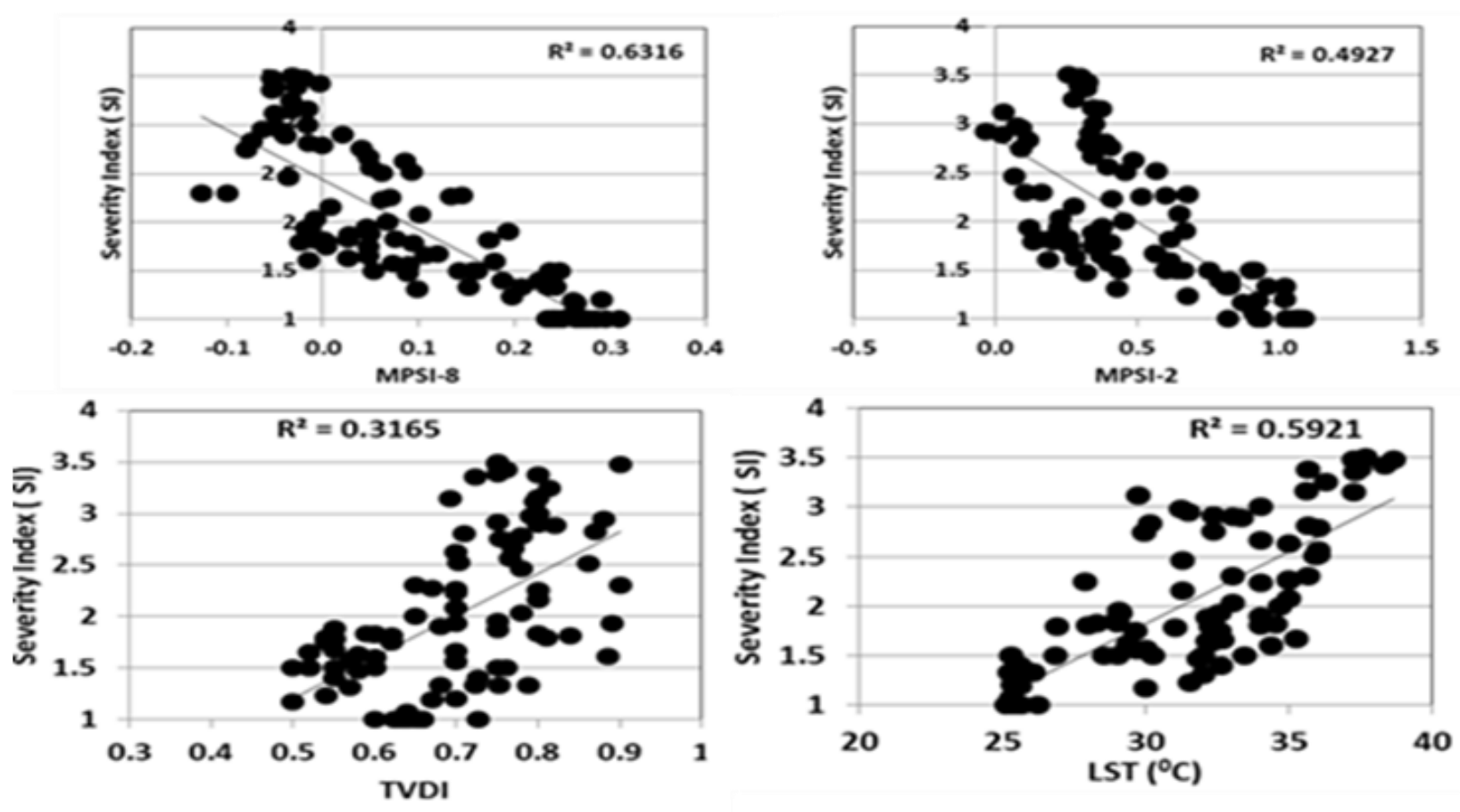

Fig. 4. Relationship between Severity Index (SI) and (a) MPSI-8 (b) MPSI-2 (c) TVDI (d) LST at different sites.

remote sensing derived index: The scatter plot (Fig.4) revealed the relationship between SI and SVI. MPSI-8 yielded negative relationship with a coefficient of determination $\left(\mathrm{r}^{2}=0.63\right)$ is shown in Fig.4a. MPSI-2 also yielded negative relation with a coefficient of determination $\left(\mathrm{r}^{2}=0.49\right)$ is shown in Fig. $4 \mathrm{~b}$. Whereas, TVDI produce low positive relation $\left(\mathrm{r}^{2}=0.31\right)$ with severity index (Fig.4c). A similar relationship of SI was found with LST and yielded $\left(r^{2}=0.59\right)$, this relationship revealed that mealybug infestation occurs in the high surface temperature zone (Fig 4d).

Remote sensing based model development for mealy bug damage assessment: Remote sensing based model was developed by using, Mealy bug Pest Stress Index-2, Mealy bug Pest Stress Index-8, Land surface temperature (LST), Temperature Vegetation Dryness Index (TVDI) as the independent variable and Severity Index (SI), dependent variable.

The developed model shows the correlation coefficient $(r=0.918)$, a high degree of relationship between severity index and predictor variables. The coefficient of determination $\left(\mathrm{r}^{2}=0.843\right)$ which explain $84.3 \%$ of the variability in mealy bug severity in the cotton crop. Adjusted $r^{2}$ value 0.836 is close to $r^{2}$, which explained $83.6 \%$ of the variability in mealy bug severity in the cotton crop. For this model, F-ratio is 119.874 , which is very unlikely to have happened by chance $(\mathrm{p}<0.001)$. The standard error of estimate (SEOE) was 0.301 . Development of a model based on spectral vegetation indices: $r=0.918 r^{2}=0.843$ Adj. $r^{2}=0.836 n=93$ Sig. at $0.001, \operatorname{SEOE}=(0.301), \mathrm{F}=119.874$

Where, $\mathrm{Y}=$ Severity Index
$\mathrm{Y}=-2.532-5.964 *$ MPSI $8+1.581 *$ MPSI $2+0.103 *$ LST $+1.436 *$ TVDI ....(4) MPSI-2, TVDI and LST shows positive relations with severity index while MPSI- 8 shows negative relation with severity index.

Fig. 5 demonstrates the scatter plot of estimated and observed value along the $1: 1$ line. This $1: 1$ line demonstrates the anticipating limit of the model with SEOE of 0.285 . In this model, the majority of the anticipated qualities are concentrated close to the $1: 1$ line which shows great precision as it matches with the observed values.

MPSI-8 has a negative value which indicates the negative relation with severity index. MPSI-2 shows a positive relationship with severity index. TVDI which represents soil moisture makes it appropriate for use in

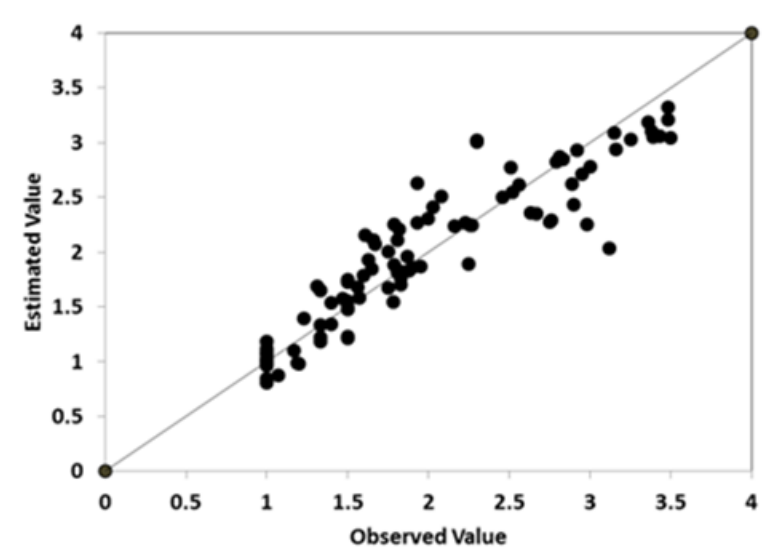

Fig. 5. 1:1 relationship between estimated and observed value by model. 

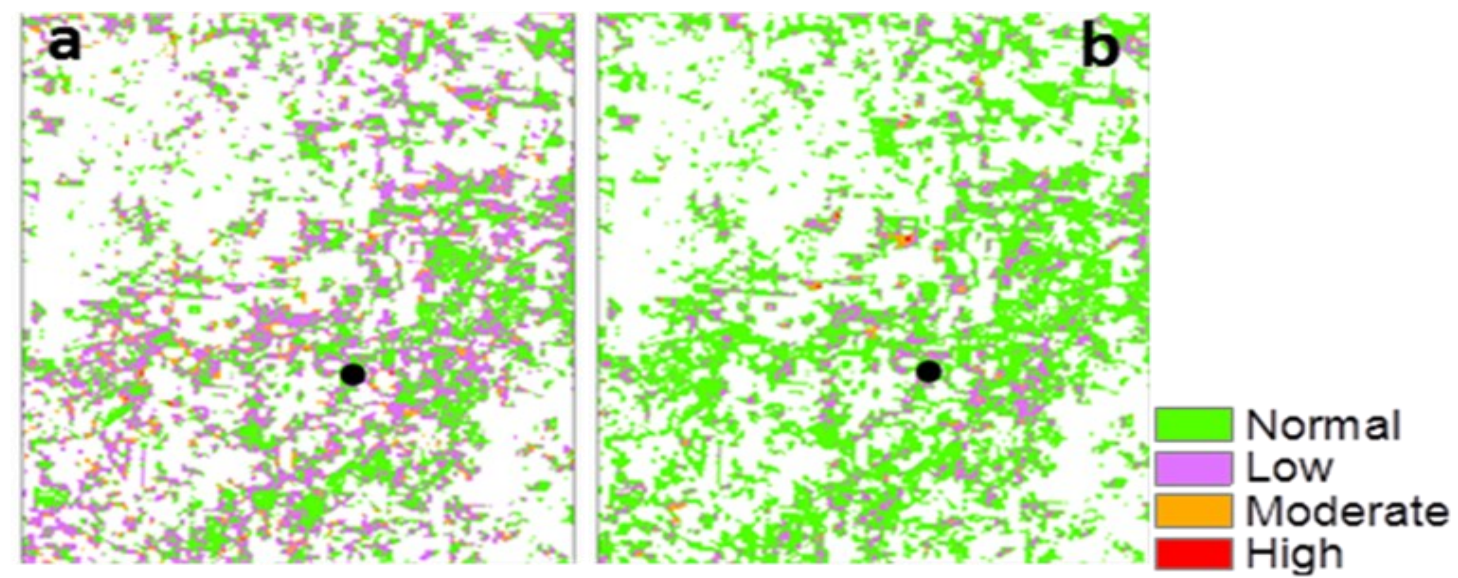

Fig. 6. (a) Spatial variation of severity of mealybug surrounding of Modanwali village, Sirsa district (21 Sept. 2009) Spatial variation of severity of mealybug surrounding of Modanwalivillage, Sirsa district (24 Sept. 2010.

soil moisture evaluation furthermore coefficient value greater than 1, also reveals the significance of TVDI in anticipating the severity of mealy bug. LST which exhibits the positive association with the mealy bug severity which shows that zone of high surface temperature favors mealy bug infestation.

Utilizing the Eq.4, connected on $21{ }^{\text {st }}$ September 2009 and $24^{\text {th }}$ September 2010, utilizing the ERDAS Imagine software's Modeller Module, Spatial distribution of mealybug on cotton appears in Fig. $6 \mathrm{a}$ and $6 \mathrm{~b}$.

The intensity of severity is classified into three categories, low, medium and high severity. Areas with low, moderate and high severity are shown by purple, orange, and red color in map respectively while area having no infestation is shown by green color.

The severity of the mealy bug was low \& moderate, covers a large area (Fig.6a) while low severity was observed in (Fig.6b) compared to the year 2009. Predicted severity of the mealybug was in accordance with ground observation. The severity of mealybug was high in the year 2009 and reduced in 2010 (Fig. 6b).

Essentially, the high reflectance of light energy in the blue and red region of visible spectra from the infested crop contrasted with a healthy crop (Fig. 3) recommends that the mealy bug infestation decreased photosynthetic pigment concentration inside the leaf structure. The spectral changes in reflectance because of mealy bug infestation in cotton found in this study are like brown plant hopper in rice (Yang et al., 2007), cotton aphid in cotton (Reisig and Godfrey, 2006), leafhopper in cotton (Prabhakar et al., 2011), late blight in potato (Dutta et al., 2014b), yellow rust in wheat (Dutta et al., 2014a), mealybug in cotton (Singh et al., 2013a,b) and green bug in wheat (Yang et al., 2005; Mirik et al., 2006 a,b). Loss of chlorophyll due to infestation by sap-feeding insects like aphids (Khawas and Khawas, 2008; Franzen et al., 2007), leafhoppers (Murugesan and Kavitha, 2010) have been reported earlier.

The noteworthy contrast in green band reflectance was seen in the healthy and mealy bug invaded cotton crop. Subsequent to the green reflectance is ascribed because of green leaf area of the crop because of which reflectance in the green region reduces. These distinctions in spectral reflectance of the healthy and the mealy bug infested cotton crop could be expected because the green band is described by generally higher reflectance because of a chlorophyll substance in the healthy crop (Jiao et al., 2006).

The outcomes show huge contrasts between mealy bug -infested and healthy cotton crop in Near Infra-Red (NIR) region. The decrease in the NIR reflectance of the mealy bug-infested cotton crop could be the development of dirty mold fungus on the honeydew discharged by the mealy bug on infested plants which damage the leave's inside structure. The changes in NIR reflectance because of mealy bug infestation found in this study are similar to dirty mold growth from scale insect-plagued citrus leaves (Gausman and Hart, 1974). High reflectance in the SWIR band could be ascribed to the loss of water from the mealybuginfested cotton crop (Fig.3) is similar to infestation of brown plant hopper on rice and increased reflectance in the SWIR region (Yang et al., 2007) and Solenopsis mealy bug in cotton that causes water stress and increase the reflectance in the SWIR band (Prabhakar et al., $2013 \mathrm{a}, \mathrm{b})$.

Thus, reflectance responses of the mealy bug-infested cotton crop show that remote sensing has the potential to detect the damage caused by mealy bug. Mealy bug infestation on cotton crop significantly increased the visible reflectance and decreased the NIR reflectance when compared with non-infested cotton. The relationships between severity index and spectral indices showed that remotely sensed data transformed into spectral indices provides a method for detecting mealy bug and differentiate damage and healthy cotton crop. In addition, the model developed in this study, applied to the satellite data produced_mealy bug severity zone maps. These maps provide detailed temporal and spa- 
tial information on mealy bug severity zone, which can be a very useful tool for mealy bug management.

\section{Conclusion}

This research shows the potential of remote sensing indices for mealy bug damage assessment in cotton. LST and TVDI yielded positive relationship with mealy bug severity having a coefficient of determination $\left(r^{2}=0.59\right)$ and $\left(r^{2}=0.31\right)$ respectively. which shows the high infestation of mealy bug in the areas of high surface temperature or low moisture area and could be mapped for identification of probable zone of mealy bug. MPSI-2 and MPSI- 8 yielded a negative relationship with mealy bug severity having a coefficient of determination $\left(r^{2}=0.49\right)$ and $\left(r^{2}=0.63\right)$ respectively. These two indices demonstrate a huge connection with mealybug infestation and able to differentiate between healthy and mealybug infested cotton crop. Furthermore, model development and validation with independent data sets showed the capability in detecting the mealybug damage, and hence can be used as a potential tool in the management of the exotic mealy bug pest.

\section{ACKNOWLEDGEMENTS}

Authors are highly grateful to Dr. S.S. Ray, Director, MNCFC, New Delhi for their encouragement to carry out this research work. Authors are highly acknowledged the NASA for their freely downloadable Land sat data facility.

\section{REFERENCES}

Aggarwal, P.K., Kalra, N., Chander, S. and Pathak, H. (2006). Info Crop: a dynamic simulation model for the assessment of crop yields, losses due to pests, and environmental impact of agro-ecosystems in tropical environments. I. Model description. Agricultural systems, 89 (1): $1-25$

Blackburn, G.A. (1998a). Spectral indices for estimating photosynthetic pigment concentrations: a test using senescent tree leaves. International Journal of Remote Sensing, 19(4): 657-675

Charleston, K., Addison, S., Miles, M. and Maas, S. (2010). The Solenopsis mealy bug outbreak in Emerald. The Australian Cotton Grower, 31: 18-22

Dutta, S., Singh, S.K. and Khullar, M. (2014a). A case study on forewarning of yellow rust affected areas on wheat crop using satellite data. Journal of the Indian Society of Remote Sensing, 42(2): 335-342

Dutta, S., Singh, S.K. and Panigrahy, S. (2014b). Assessment of late blight induced diseased potato crops: A Case Study for West Bengal District Using Temporal AWiFS and MODIS Data. Journal of the Indian Society of Remote Sensing, 42(2): 353-361

El-Khawas, M. and El-Khawas, M. (2008). Interactions between Aphis gossypii (Glov.) and the common predators in eggplant and squash fields, with evaluating the physiological and biochemical aspects of biotic stress induced by two different aphid species, infesting squash and cabbage plants. Australian Journal of Basic and Applied Sciences, 2(2): 183-193

Franzen, L.D., Gutsche, A.R., Heng-Moss, T.M., Higley, L. G., Sarath, G. and Burd, J.D. (2007). Physiological and biochemical responses of resistant and susceptible wheat to injury by Russian wheat aphid. Journal of Economic Entomology, 100(5): 1692-1703

Gamon, J. and Surfus, J. (1999). Assessing leaf pigment content and activity with a reflecto meter. New Phytologist, 143(1): 105-117.

Gates, D. M. (1970). Physical and physiological properties of plants. Remote Sensing with Special Reference to Agriculture and Forestry: With Special Reference to Agriculture and Forestry, 224-252

Gausman, H. and Hart, W. (1974). Reflectance of sooty mold fungus on citrus leaves over the 2.5 to 40 -micrometer wavelength interval. Journal of Economic Entomology, 67(4): 479-480

Jhala, R., Bharpoda, T. and Patel, M. (2008). Phenacoccus solenopsis Tinsley (Hemiptera: Pseudococcidae), the mealy bug species recorded first time on cotton and its alternate host plants in Gujarat, India. Uttar Pradesh Journal of Zoology, 28(3): 403-406

Jiao, H., Zha, Y., Gao, J., Li, Y., Wei, Y. and Huang, J. (2006). Estimation of chlorophyll $\square$ a concentration in Lake Tai, China using in situ hyper spectral data. International Journal of Remote Sensing, 27(19): 4267-4276

Kranthi, K.R., Kranthi, S., Kumar, R., Nagrare, V.S., and Barik, A. (2009a). Advances in Cotton IPM. Technical Bulletin, Central Research Institute for Cotton Research, Nagpur, India. pp. 26

Mirik, M., Michels, G., Kassymzhanova-Mirik, S., Elliott, N., Catana, V. and Jones, D. (2006a). Using digital image analysis and spectral reflectance data to quantify damage by greenbug (Hemitera: Aphididae) in winter wheat. Computers and Electronics in Agriculture, 51 (1): 86-98

Mirik, M., Michels, G.J., Kassymzhanova-Mirik, S., Elliott, N.C. and Bowling, R. (2006b). Hyperspectral spectrometry as a means to differentiate uninfested and infested winter wheat by greenbug (Hemiptera: Aphididae). Journal of Economic Entomology, 99(5): 1682-1690

Monga, D., Kumar, R., Pal, V. and Jat, M. (2009). Mealybug, a new pest of cotton crop in Haryana-a survey. Journal of Insect Science, 22: 100-103

Murugesan, N. and Kavitha, A. (2010). Host plant resistance in cotton accessions to the leaf hopper Amrasca devastans (Distant). Journal of Biopesticides, 3(3): 526-533

Peñuelas, J. and Filella, I. (1998). Visible and near-infrared reflectance techniques for diagnosing plant physiological status. Trends in Plant Science, 3(4): 151-156

Prabhakar, M., Prasad, Y., Thirupathi, M., Sreedevi, G., Dharajothi, B. and Venkateswarlu, B. (2011). Use of ground based hyperspectral remote sensing for detection of stress in cotton caused by leafhopper (Hemiptera: Cicadellidae). Computers and Electronics in Sgriculture, 79(2): 189-198

Prabhakar, M., Prasad, Y.G., Desai, S., Thirupathi, M., Gopika, K. and Rao, G.R. (2013a). Hyperspectral remote sensing of yellow mosaic severity and associated pigment losses in Vigna mungo using multinomial logistic regression models. Crop Protection, 45: 132-140 
Prabhakar, M., Prasad, Y.G., Vennila, S., Thirupathi, M., Sreedevi, G. and Rao, G.R. (2013b). Hyperspectral indices for assessing damage by the solenopsis mealybug (Hemiptera: Pseudococcidae) in cotton. Computers and Electronics in Agriculture, 97: 61-70

Reisig, D. and Godfrey, L. (2006). Remote sensing for detection of cotton aphid-(homoptera: aphididae) and spider mite-(acari: tetranychidae) infested cotton in the San Joaquin Valley. Environmental Entomology, 35(6): 1635-1646

Richardson, A., Aikens, M., Berlyn, G. and Marshall, P. (2004). Drought stress and paper birch (Betula papyrifera) seedlings: effects of an organic biostimulant on plant health and stress tolerance, and detection of stress effects with instrument-based, noninvasive methods. Journal of Arboriculture, 30: 52-61

Sandholt, I., Rasmussen, K. and Andersen, J. (2002). A simple interpretation of the surface temperature/vegetation index space for assessment of surface moisture status. Remote Sensing of Environment, 79(2): 213-224

Schott, J.R. and Volchok, W.J. (1985). Thematic Mapper thermal infrared calibration. Photogrammetric Engineering and Remote Sensing, 51: 1351-1357

Sims, D.A. and Gamon, J.A. (2002). Relationships between leaf pigment content and spectral reflectance across a wide range of species, leaf structures and developmental stages. Remote Sensing of Environment, 81(2): 337-354
Singh, S., Dutta, S. and Dharaiya, N. (2013a). Efficiency of remote sensing indices in crop biotic stress assessment. International Journal for Life Sciences and Educational Research, 1(3): 100-104

Singh, S., Dutta, S. and Dharaiya, N. (2013b). Evaluation of probable hot spots of mealybug concentration in cotton growing areas of Sirsa district using satellite data. International Journal for Life Sciences and Educational Research, 1(2): 115-119

Singh, S., Dutta, S. and Dharaiya, N. (2016). Mapping of cotton mealybug (Hemiptera: Pseudococcidae) damage in Sirsa district, Haryana using Geospatial technique. International journal of Engineering Sciences \& Research Technology, 5(2): 138-146

Tanwar, R.K., Jeyakumar, P., and Monga, D. (2007). Mealy bugs and their management. New Delhi.

Yang, C.M., Cheng, C.H. and Chen, R.K. (2007). Changes in spectral characteristics of rice canopy infested with brown plant hopper and leaf folder. Crop Science, 47 (1): 329-335

Yang, Z., Rao, M., Elliott, N., Kindler, S. and Popham, T. (2005). Using ground-based multispectral radiometry to detect stress in wheat caused by green bug (Homoptera: Aphididae) infestation. Computers and Electronics in Agriculture, 47(2): 121-135 